\title{
HACIA LA CONSTRUCCIÓN DEL TURISMO RURAL EN LA COLONIA 20 DE ABRIL- DARÍO SANTILLÁN
}

\section{UNA EXPERIENCIA DE DESARROLLO RURAL DESDE EL} ENFOQUE DE LA NUEVA RURALIDAD

Gerardo Castro

Grupo de Estudios Rurales, Departamento de Ciencias Sociales, Universidad Nacional de Luján / CONICET. Luján, Argentina

iD 0000-0002-1521-3215

$>$ gcastounlu@gmail.com

\section{Natalia Kindernecht}

Grupo de Estudios Rurales, Departamento de Ciencias Sociales, Universidad Nacional de Luján/ CONICET. Luján, Argentina

iD $0000-0002-1258-8628$

D nati.kinder@yahoo.com
María Milva Fontana

Grupo de Estudios Rurales, Departamento de Ciencias Sociales, Universidad Nacional de Luján Luján, Argentina

(iD) 0000-0002-2359-7044

gerurales@gmail.com

\author{
Gabriela Paola Lencina \\ Grupo de Estudios Rurales, Depar- \\ tamento de Ciencias Sociales, \\ Universidad Nacional de Luján \\ Luján, Argentina \\ (iD) 0000-0003-2451-0905 \\ gabrielaplencina@gmail.com
}

\section{Gisela Paola Reposo}

Grupo de Estudios Rurales, Departamento de Ciencias Sociales, Universidad Nacional de Luján Luján, Argentina

(iD) $0000-0002-7233-1074$

gireposo@gmail.com

\section{RESUMEN}

En 2015 un grupo de productores/as hortícolas, organizados en la Unión de Trabajadores de la Tierra (UTT), tomó un predio de 80 hectáreas en Jáuregui, Luján. En él se lleva adelante la producción agroecológica de hortalizas con vistas al abastecimiento local. Esta experiencia se convierte rápidamente en un atractivo para los/las consumidores/ as por las características productivas, comerciales, políticas, culturales y ambientales del emprendimiento. La presente ponencia busca analizar y sistematizar el caso de la colonia agrícola 20 de Abril Darío Santillán. Este constituye, en el marco de las recientes transformaciones en las producciones de abasto de la interfase rural-urbana, en la construcción de una propuesta de turismo rural en el partido de Luján. A estos fines, se presentan resultados del trabajo de campo realizado desde 2018, a partir del proyecto de extensión universitaria "Fontalecimiento del Turismo Rural en la Colonia Agrícola Integral de Abastecimiento Urbano 20 de abril Darío Santillán", el cual consistió en encuentros, visitas, recorridas prediales y talleres realizados junto con los/las productores/as.

\section{PALABRAS CLAVE}

turismo rural $>$ agroecología $>$ nueva ruralidad $>$ horticultura $>$ colonia hortícola

HACIA LA CONSTRUCCIÓN DEL TURISMO RURAL EN LA COLONIA 20 DE ABRIL-DARÍO SANTILLÁN UNA EXPERIENCIA DE DESARROLO RURAL DESDE EL ENFOQUE DE LANUEVA RURAUDAD

\section{Autores:}

Gerardo Castro, Naralia Kindemecht, María Milva Fontana, Gabriela Lencina, Gisela Reposo
Recibido

4 de agosto, 2020

Aprobado

2 de octubre, 2020

DOI

https://doi.org/10.24215/27186717e011
Ayana Revista de Investigación en Turismo

| Año 2 | Vol. 2 | № 01 Diciembre 2021 Mayo 2022

ISSN 2718-6717

Entidad editora Instituto de Investigaciones en Turismo, Facultad de Ciencias Económicas (Universidad Nacional de La Plata) La Plata I Buenos Aires I Argentina

http://revistas.un/p.edu.ar/ayana 


\section{Ayana \\ Revista de Investigación en Turismo}

\section{TOWARDS THE CONSTRUCTION OF RURAL TOURISM IN COLO- NIA 20 DE ABRIL DARÍO SANTILLÁN. AN EXPERIENCE OF RURAL DEVELOPMENT FROM THE PERSPECTIVE OF THE NEW RURALITY}

\section{ABSTRACT}

In 2015, a group of horticultural producers organised in the Union of Land Workers (Unión de Trabajadores de la Tierra, UTT), took over an 80-hectare property in Jáuregui, Luján. Agro-ecological production of vegetables is carried out there with a view to supplying the local market. This experience quickly became attractive to consumers due to the productive, commercial, political, cultural, and environmental characteristics of the enterprise. This paper seeks to analyse and systematise the case of the agricultural colony "20 de Abril Darío Santillán" in its construction of a rural tourism proposal in the Luján district and within the framework of the recent transformations in supply productions of the rural-urban interface. The results of the field work carried out since 2018 are presented from the university extension project "Strengthening Rural Tourism in the Integral Agricultural Colony of Urban Supply 20 de abril Darío Santillán", which consisted of meetings, visits, property tours, and workshops carried out with the producers.

\section{KEYWORDS}

rural tourism $>$ agro-ecology $>$ new rurality $>$ horticulture $>$ horticultural colony

\section{RUMO À CONSTRUÇÃO DO TURISMO RURAL NA COLÔNIA 20 DE ABRIL DARÍO SANTILLÁN. UMA EXPERIÊNCIA DE DESENVOLVI- MENTO RURAL DESDE A PERSPECTIVA DA NOVA RURALIDADE}

\section{RESUMO}

Em 2015, um grupo de horticultores organizado na União dos Trabalhadores da Terra (UTT), assumiu uma propriedade de 80 hectares em Jáuregui, Luján. Nela, a produção agroecológica de hortaliças é realizada visando o abastecimento local. Esta experiência rapidamente se torna um atrativo para os consumidores devido às características produtivas, comerciais, políticas, culturais e ambientais do empreendimento. Este documento/esta pesquisa pretende realizar uma sistematização e análise do caso da colônia agrícola "20 de abril - Darío Santillán" na construção de uma proposta de turismo rural no distrito de Luján e no marco das recentes transformações na oferta de produção da interface rural-urbana. Os resultados do trabalho de campo realizado desde 2018 são apresentados a partir do projeto de extensão universitária "Fortalecimento do Turismo Rural naColônia Agrícola Integral de Abastecimiento Urbano 20 de abril Darío Santillán", que consistiu em reuniões, visitas, visitas às propriedades e workshops realizados em conjunto com os produtores.

\section{PALAVRAS CHAVE}

turismo rural $>$ agroecologia $>$ nova ruralidade $>$ horticultura $>$ colônia hortícola 


\section{Introducción}

Pensar la ruralidad actual en la periferia del Gran Buenos Aires (GBA) implica contemplar diversos procesos que, en las últimas décadas, han complejizado estos ámbitos de tradición agropecuaria. Estas áreas pueden identificarse como una interfase rural-urbana, dada la heterogeneidad, dinamismo y conflictividad territorial propias de la frontera entre el campo y la ciudad. El partido de Luján, localizado al oeste del GBA y a $80 \mathrm{~km}$ de la Ciudad Autónoma de Buenos Aires (CABA), forma parte de esta interfase, donde han impactado - desde fines del siglo $\mathrm{XX}$ - tanto los procesos de urbanización como el capital agrario. Asimismo, este fenómeno propició una intensa competencia por la ocupación y uso del suelo, y generó numerosas tensiones entre los sujetos (González Maraschio, 2011, 2012).

Luján es, a su vez, un espacio de producción de alimentos. Aunque la tradicional cuenca de lácteos se ha desdibujado a partir de la elevada rentabilidad de nuevos usos agrarios y extra-agrarios del territorio, relevamientos recientes han mostrado la existencia en expansión de productores familiares hortícolas (González Maraschio et al. 2017). Un grupo de reciente radicación es el de la Colonia 20 de abril Darío Santillán', integrada por productores nucleados en la Unión de Trabajadores de la Tierra (UTT) que arribaron al partido en 2015. Allí, construyeron una propuesta hortícola alternativa basada en la producción de verduras y hortalizas sin agroquímicos y orientada al abastecimiento local mediante canales cortos de comercialización (Castro, 2019).

Esta experiencia, junto a otras de la zona con similares propuestas, construye en el partido una nueva ruralidad no hegemónica. Surgen desde organizaciones de la economía social, con eje en la soberanía alimentaria y la agroecología, que facilitan el acceso a la tierra por parte de familias expulsadas de un mercado altamente competitivo y protagonizada por productores descapitalizados, en gran medida de origen migrante, que encuentran en la acción colectiva (Giarraca, 2002) oportunidades productivas, educativas y de participación política, entre otras. A la vez, esta ruralidad alternativa se sostiene por un creciente número de consumidores conscientes (Craviotti \& Soleno Wilches, 2015), ambiental y socialmente comprometidos, que buscan alimentos "sin venenos", tener contacto con quienes los producen en espacios de venta directa (Caracciolo, 2014) y, eventualmente, conocer e involucrarse en la forma de producirlos.

La Colonia se ha visibilizado y diferenciado, por su ruralidad alternativa, constituyéndose como un atractivo que actualmente sustenta una propuesta turística sobre la que se orienta este trabajo. A lo largo de estas páginas se intentarán responder las siguientes preguntas: ¿̇Cómo se produce la ruralidad de la Colonia? ¿̇Cuáles son los elementos que se valorizan para una práctica turística? ¿̇n qué consiste la propuesta turística de la Colonia 20 de abril?

Para ello, se ha adoptado una metodología cualitativa a partir del trabajo de campo realizado desde 2018 y que actualmente continúa en el marco del proyecto "Fortalecimiento del Turismo Rural en la Colonia Agrícola Integral de Abastecimiento Urbano -20 de abril- Darío Santillán" ${ }^{\prime 2}$. Se utilizará información primaria relevada mediante numerosos encuentros de trabajo, visitas, recorridas de planificación y talleres, realizados por el equipo de extensión durante el período analizado.

${ }^{1}$ A partir de ahora nos referiremos a este colectivo como la Colonia debido a que se trata de una denominación de uso cotidiano para los/as productores/as, quienes realizamos esta investigación y extensión en/con el espacio y los consumidores que la frecuentan

2 Proyecto de Extensión UNLu. Disposición CD-CS No 206-20. Director, Gerardo Castro y Co-directora, Fernanda González Maraschio. 
Nuestra aproximación a la temática parte del análisis territorial sobre las transformaciones recientes en las producciones de abasto, por lo que nuestro foco está puesto en la producción de una ruralidad alternativa y la construcción de una identidad territorial, que actualmente busca ponerse en valor mediante el turismo y no en la práctica turística en sí misma. Entendemos que este caso no logra ajustarse completamente a los cánones del turismo rural en sentido amplio, por lo que indagaremos en estas líneas teóricas sin encasillar la experiencia en las categorías más difundidas.

\section{Aproximación teórica: ¿̇Qué ruralidad? ¿̇Qué turismo?}

La multidireccionalidad de las relaciones entre los espacios urbanos y rurales producto del avance de la globalización y los cambios en los patrones culturales, promueven que el espacio rural sea consumido por habitantes urbanos, estableciéndose nuevos vínculos y relaciones, a partir de determinadas valoraciones subjetivas que les son atribuidos (Craviotti, 2007; Sili, 2019). Algunas de estas, se basan en búsquedas de un pasado idílico o una idealización de lo rural (Zusman \& Pérez Winter, 2018) despojado de conflictos. De esta manera, el campo, según Bell (2006, p. 2), es un paisaje manufacturado, "producto del imaginario burgués que emergió con la cultura urbana-industrial moderna y que buscaba producir una espacialización social ordenada de margen y centro". En este sentido, algunos enfoques ponen énfasis en la construcción de una nueva ruralidad en donde destacan las transformaciones socio-territoriales de las últimas décadas y el rol de las producciones familiares en este contexto.

Esta revalorización del campo y las múltiples actividades que alberga, han promovido estudios que se enfocan en distintas corrientes de análisis sobre la construcción de diversas ruralidades. Uno de los más recientes es el de Castro (2018), que retoma algunas perspectivas de los enfoques de la multifuncionalidad del campo y la nueva ruralidad. Los enfoques de la multifuncionalidad rural están ligados a la incorporación de servicios no agropecuarios que surgen por su anexión a la ciudad y se corresponden con una visión europea del campo, donde la agricultura de tiempo parcial está extendida. Una subvariante de este enfoque en América Latina es el de la multifuncionalidad desde una visión normativa, en América Latina, este se tradujo en un conjunto de políticas públicas ligadas a organismos internacionales que tuvieron (y tienen) como objetivo paliar los problemas causados por el avance del capitalismo en el agro y la subordinación de determinados sujetos (Castro, 2018). Plantea un desarrollo rural fuertemente anclado en lo local y en las características de los lugares, donde la capacidad de competir globalmente es indispensable para la viabilidad económica del territorio rural. Las políticas deben producir una transformación productiva que conecte tanto a los actores locales entre sí como con los mercados externos. Asimismo, dichas políticas buscan eliminar las reglas que excluyen a los sectores postergados y reproducen la pobreza (Schejłman \& Berdegué, 2007).

Por otro lado, existen dos miradas que rescatan nuevas tendencias y escapan al análisis de la multifuncionalidad. En la primera, la nueva ruralidad aparece como producto de la degradación ambiental, la utilización de los paquetes tecnológicos, el aumento de la explotación y la subordinación de la pequeña producción a los grupos concentrados que acaparan tierra y recursos. Es decir, una nueva ruralidad "no deseable" que debería ser cambiada (Castro, 2018). En cuanto a la segunda, la que nos interesa destacar, corresponde a una vertiente de carácter propositivo y alineada con la propuesta turística que surge desde los/las productores/as nucleados/as en la Colonia. Se trata de la nueva ruralidad desde una visión comunitaria (Kay, 2008) o solidaria (Castro, 2018). 
Esta surge a partir de las estrategias de los sujetos rurales y urbanos de plantear alternativas posibles para garantizar su reproducción y mejorar las condiciones de producción y consumo. A su vez, esta variante tiene que ver con la persistencia de los sectores subalternos del agro en la producción agropecuaria, ligadas a fenómenos de pluriactividad y crecimiento de actividades no agropecuarias, sin que esto signifique el alejamiento de las familias productoras de lo agrario, más bien, un proceso de resistencia y contrahegemonía ante los avances de la globalización neoliberal (Castro, 2018).

Entendemos que la propuesta turística de la Colonia se encuadrada en esta última vertiente pues se orienta a revalorizar aquellos elementos que componen la historia de la organización y los procesos colectivos que dieron lugar al emprendimiento. En este sentido, la agroecología constituye un eje central en el proceso de construcción de una identidad capaz de multiplicar prácticas ideales y de formar parte de un proceso de visibilización de las luchas de la agricultura familiar.

Al mismo tiempo, el atractivo turístico no se construye a partir de atributos absolutos del lugar, se da en términos relacionales, con la sociedad de origen de los turistas. La producción agroecológica y el predio donde se desarrolla es valorada positivamente, tanto por productores como por visitantes. En este sentido, Bertoncello (2002) plantea que

cada lugar de la superficie terrestre se caracteriza por un conjunto de rasgos que le son propios, rasgos sociales, culturales y también naturales; la valorización de alguno de ellos como atractivo turístico se procesa no por su valor intrínseco ni por la lógica de la sociedad de ese lugar. Pero una vez transformado en atractivo, ese rasgo o atributo seleccionado como tal cobra este carácter, y en tomo a él se va a procesar la valorización turística (Bertoncello, 2002:43).

El turismo rural, pensado desde la Colonia, tiene que ver con un conjunto de propuestas que tienden a diversificar los ingresos prediales, brindar una salida laboral a las nuevas generaciones sin que estos se alejen de lo rural y generar a futuro un proceso de educación ambiental junto con la comunidad. Se apela a la valoración de elementos patrimoniales naturales e histórico-culturales como una forma de afianzar la actividad agropecuaria alternativa. También, se propone enfrentar a los visitantes con contradicciones propias de la producción de alimentos que se extienden fuera de los límites del predio y las lógicas de agronegocio (Castro y Kindernecht, 2017; González Maraschio et. al. 2019). De este modo, se pone en evidencia, un campo real que no es ajeno los problemas ambientales y demás conflictos, pero que tampoco cesa de buscar alternativas.

En línea con el planteo de Pérez Winter,

el turismo se expresa -material y simbólicamente- en el espacio donde se desarrolla, conformando diversos tipos de territorios turísticos que convivirán con otras territorialidades, no siempre armónicamente, ya que el proceso no se encuentra exento de la producción y reproducción de relaciones asimétricas de poder y conflictos existentes en el interior de la trama social local (2017, p.265). 
La visibilización de los atractivos escénicos, del patrimonio, del sistema agroproductivo y de las características culturales de los/as colonas garantiza a los visitantes una experiencia de desarrollo rural compartida entre productores y compradores. Estos, pasan a ser protagonistas de las luchas que emprenden los/las agricultoras por la tierra, la salud, la educación, la equidad de género. Asimismo, promueven los valores de la agroecología, el comercio justo y las luchas campesinas. Pero dichos procesos también están atravesados por las dinámicas contrapuestas que componen el territorio de la interfase.

\section{La producción hortícola en la interfase rural-urbana}

Entendemos que estos ámbitos están atravesados por fuerzas en equilibrio inestable que producen territorios de estructuras amosaicadas, producto de la alternancia de usos del suelo. En Luján, el desarrollo de barrios cerrados que se extienden desde el partido de Pilar, despliega en el territorio un proceso especulativo que, conjuntamente con los cultivos extensivos, en particular el de soja, desalientan la producción de alimentos que se orienta al abastecimiento local (González Maraschio et al. 2015). En consecuencia, el partido experimenta transformaciones propias del área pampeana a partir de los procesos de agriculturización/sojización que se extienden desde la zona núcleo. En la campaña 2018/2019 la soja ascendió a 14.700 hectáreas, más de la mitad de la superficie cultivada de Luján. Por otro lado, la urbanización de tipo expandido ha cobrado fuerza a partir de la culminación de las obras del Acceso Oeste, a finales de la década del 90. En particular, la localización de Urbanizaciones Cerradas compite con los usos agropecuarios que redunda, además, en la suba de los precios de la tierra (González Maraschio et. al, 2016). A pesar de ambos fenómenos, las producciones hortícolas se encuentran en crecimiento (Castro, 2020). Esto se da en el marco de una profunda reestructuración de la actividad hortícola que se ha producido desde los '90 pero con énfasis luego de la crisis 2001/02. En ese contexto, La Plata se consolidó como el espacio productivo más importante, mientras que el resto de los espacios periféricos del GBA se centran en revender sus productos y configuran un archipiélago productivo (García y Le Gall, 2009) altamente especializado. En los vínculos que se establecen en este esquema, Luján experimenta la llegada de productores que son desplazados de partidos cercanos, donde la competencia por los usos del suelo es mayor: Pilar, Moreno y Escobar, pero también La Plata. La hipercompetitividad, las condiciones flexibles del arrendamiento y la intensificación del capital requerida para mantenerse en la actividad, expulsa productores hacia otras áreas. Un ejemplo de este grupo son los productores de la Colonia. Se trata, en su mayoría, de trabajadores oriundos de Tarija (Bolivia) que arribaron a Argentina entre finales de los años 90 y principios del 2000. Algunos, han recorrido buena parte de los espacios productivos de nuestro país (Jujuy, Mar del Plata, Mendoza, Córdoba, Corrientes) antes de organizarse en La Plata, dentro de la UTT. En esa trayectoria llevaron a cabo un manejo convencional, en función de poder mantenerse dentro de los mercados, para garantizar su reproducción. García (2015b) ha denominado este proceso como un "funcionamiento espiral" del modelo hortícola platense, donde mediante la aplicación creciente de tecnología se incrementa la producción. De este modo, se reducen los precios y, consecuentemente, las ganancias, al tiempo que se impulsa a los productores hortícolas a incorporar mayor tecnología. Sin embargo, este modelo conduce a la concentración de la producción, al aumento de la presión sobre los ecosistemas y a la reproducción de condiciones 
de vida paupérrimas, basadas en la explotación de la mano de obra. En contraposición, la acción colectiva le ofrece a los productores, mediante la transición a la agroecología, la posibilidad de acceder a la tierra propia (o en comodato). A su vez, los libera de la dependencia de insumos externos y la explotación de la fuerza de trabajo, aunque este tipo de producción deba soportar los avances de las pulverizaciones de los cultivos extensivos. Es decir, coexistir con actividades industriales y otras dinámicas propias de la interfase.

El arribo de los productores de la Colonia ha despertado un gran interés a nivel local en torno a la producción y distribución de alimentos. Asimismo representa una nueva ruralidad que consideramos alternativa por tratarse de un proceso que viene a revertir la merma de las producciones hortícolas al oeste de GBA (Kindernecht, 2020); pero también es renovar un discurso, que permea en las políticas públicas acerca del abastecimiento de hortalizas, la soberanía alimentaria y el acceso a la tierra.

\section{La Colonia 20 de Abril}

La Colonia 20 de Abril Darío Santillán es un espacio perteneciente a la Unión de Trabajadores de la Tierra (UTT), organización que nuclea a productores frutihortícolas con carácter federal pero con una fuerte presencia en La Plata, capital de la provincia de Buenos Aires. La organización excede, en sus reivindicaciones, las esferas productivas y comerciales e incorpora y visibiliza el debate por el acceso a la tierra, la agroecología, las cuestiones de género, la educación y la salud comunitaria, a través de novedosas formas acción colectiva (Giarracca, 2002) como verdurazos y feriazos (distribución de verduras de forma gratuita o a muy bajo precio en lugares centrales como Plaza de Mayo, y demás intervenciones en espacios públicos).

En el año 2015, la UTT emprendió dos intentos de ocupación simultánea en terrenos pertenecientes al Estado (ambos a 85 km., aproximadamente, de CABA): una en Campana, resistida por los vecinos; y otra en Jáuregui, donde se ocuparon 80 has. del ex instituto Ramayón López Valdivieso, perteneciente al Ministerio de Desarrollo Social de la Nación. La estrategia organizacional se basó en la toma y en una fuerte vinculación con el Estado, a partir de la negociación con distintos espacios de gobierno (Municipal, Provincial, Nacional). Esto, derivó en la regularización de la tenencia a partir de un comodato por cinco años supeditado a la producción agroecológica con vistas al abastecimiento urbano (recientemente extendido a veinte).

Partiendo de diversas estrategias, la colonia se fue integrando gradualmente a la comunidad local. En sus inicios, se llevó a cabo una presentación personal por parte de los y las productores/as en el barrio lindante a la colonia. Luego, se repartieron volantes y se comentó el proyecto, se donaron alimentos de producción propia a comedores cercanos y comenzaron a participar en ferias locales. Los bolsones de verduras se comercializaron a través de nodos, principalmente, mediante la venta predial, primero, a través de la Feria Agroecológica y, actualmente, en el Almacén de Campo de la UTT que funciona dentro del predio.

Esta experiencia, además de ser pionera en la zona, marca un antecedente en los procesos de recuperación de tierra y puesta en valor por parte de familias productoras. En la colonia, numerosos actores institucionales han realizado aportes con el fin de contribuir a la sustentabilidad del agroecosistema y la mejora de la calidad de vida de las 35 
familias que hoy en día la habitan, como así también los consumidores de sus productos. En distintos puntos de la interfase, se están desarrollando emprendimientos similares con diverso modo de gestión, pero con una fuerte presencia de los gobiernos municipales y organizaciones de pequeños productores: en las localidades bonaerenses de Mercedes (Colonia Agroecológica UTT-Municipio), Moreno (Parque Agrario Agroecológico Municipal), San Vicente (Colonia Agrícolas UTT) y Cañuelas (Colonia Agrícola UTT); en la provincia de Entre Ríos, la colonia de Gualeguaychú (UTT), y en Corrientes, la de Puerto Piray (UTT).

\section{Organización}

Además, de los aspectos referidos a la práctica productiva-agroecológica, como la fabricación de bioinsumos y el galpón de empaque (donde la verdura es lavada, pesada y preparada para la comercialización), funcionan un espacio de terminalidad educativa de nivel primario y secundario oficiales, una oficina de la Secretaría de Agricultura Familiar Campesina e Indígena, delegación PBA, espacios de salud comunitaria y de discusión sobre temas de género, con el objetivo de mejorar las condiciones de las familias productoras. La organización de la Colonia se instrumenta mediante una asamblea de productores donde se discuten aspectos referidos a la producción, comercialización y temas ligados a la organización del predio. La figura política principal en el emprendimiento es el delegado, quien tiene la función de representar las demandas de la asamblea en otras instancias de participación de la UTT. En paralelo, se mantienen mesas de apoyo donde participan otras organizaciones de la sociedad civil, como representantes de universidades, docentes, referentes de otras organizaciones y ferias.

\section{Producción y Comercialización}

Cada familia productora cuenta con una parcela de 1 ha de superficie otorgada para su usufructo mediante un comodato firmado con el municipio. En algunos casos, el área controlada es mucho menor debido a la capacidad productiva de la unidad familiar y otros factores externos al hogar, como la poca nivelación del terreno que hace que sea inundable. Más allá de este aspecto, el acceso a la tierra ha significado para los productores un cambio significativo en su calidad de vida debido al contraste con la producción que realizaban en La Plata, donde las condiciones de contratación y los precios excesivos dejaban un escaso margen de ganancia. Esta situación, los obligaba a usar agroquímicos para mantener el rendimiento y la competitividad (según entrevistas realizadas en 2019), lo que redunda en el funcionamiento espiral antes descrito.

La producción en la Colonia 20 de Abril se realiza bajo las premisas de la agroecología. En líneas generales, esta práctica incluye muchos más aspectos que la no utilización de agroquímicos de síntesis química. La agroecológica como disciplina científica incluye las dimensiones agroproductivas, socioeconómicas y culturales desde una crítica a los modelos hegemónicos de producción (Sevilla Guzmán \& Woodgate, 2013; Sevilla Guzmán, Sarandón \& Flores, 2014).

Siguiendo la tendencia predominante de la horticultura, en la colonia el trabajo es fundamentalmente familiar. Los hogares se abocan completamente a las actividades prediales sin presentarse hasta el momento casos de pluriactividad, debido, probablemente, a las largas horas que demanda el cuidado de las quintas. Sin embargo, el cambio en las condiciones de producción en La Plata, permitió a los productores retomar estudios. 
Una de las problemáticas visibilizadas por la organización fue la inclusión de las juventudes en la actividad; debido a cambios en la escolarización y motivaciones personales, prefieren no continuar con el trabajo hortícola. De este modo, se ha conformado un equipo de comercialización de jóvenes que descomprime las funciones comerciales y de atención al público recaídas en los productores y brinda un ingreso económico a los y las participantes.

Culturalmente, el trabajo de gestión y negociación en la horticultura se lo ha asociado con rol de los varones, mientras que las tareas productivas de las mujeres en las quintas han sido invisibilizadas, mediante la categorización de ayuda. De la misma manera, la reproducción de la fuerza de trabajo recae sobre sus espaldas, el cuidado de los/las niñas y su educación, la preparación de la comida (Ambort, 2019). Pero también las tareas referidas a la organización política y comunitaria, como la militancia en organizaciones gremiales, merenderos, entre otros. La creación de espacios de discusión desde esta perspectiva tiende a generar rupturas dentro de las organizaciones, aunque estos cambios en los patrones de reproducción de las desigualdades de género y otros tipos de violencias sobre las mujeres son frecuentes y difíciles de erradicar.

Tanto agricultores como agricultoras de la colonia realizan jornadas de limpieza y mantenimiento de los espacios comunes de la colonia. Además, el trabajo recíproco es frecuente en momentos claves de la producción hortícola.

La comercialización apunta a abastecer al partido de Luján y zonas aledañas mediante un circuito corto de comercialización que sigue los principios de la Economía Social y Solidaria (ESS). A diferencia de los mercados capitalistas hegemónicos, donde prima la ganancia, los mercados de la ESS se basan en el trabajo de sus integrantes y cuentan, en muchos casos, con ayuda estatal. Pero lo más importante es que eliminan la intermediación y establecen relaciones recíprocas entre compradores y productores. Esta vinculación se asienta en aspectos relacionados con el precio justo, la equidad de género y la preocupación por un ambiente sano (Caracciolo, 2014).

Los principales canales de comercialización son los siguientes:

- Almacenes de Ramos Generales y de campo (UTT): llamados así por la variedad de productos que ofrecen. Es una estrategia de la organización para promover el consumo de verdura agroecológica y absorber parte de la producción de sus miembros. Cuentan con varias sucursales en la Ciudad de Buenos Aires y ofrecen, además de hortalizas agroecológicas, productos provenientes de otras cooperativas y organizaciones sociales. En la colonia funciona, tres veces por semana, el Almacén de Campo, en el cual se comercializan verduras producidas en el predio y en otras regionales de la UTT. Asimismo se venden productos orgánicos y agroecológicos elaborados en cooperativas y/o por organizaciones sociales.

- Ferias agroecológicas: si bien la colonia contaba con una feria propia, se vio interrumpida durante la pandemia, razón por la cual cobró mayor impulso la organización del Almacén. En la actualidad, los productores participan en ferias agroecológicas municipales, como es el caso del Mercado Sustentable (municipal) en el Paseo Calelian, en Luján o el Feriazo Agroecológico (Gobierno provincial, municipal) en la localidad de San Martín.

- Red de nodos: se trata de una forma de vincular a los consumidores con los productos de la colonia y promover una fuente de ingresos. La red como estrategia establece el reparto de bolsones entre 5 y 7 kilos de verduras variadas que se preparan en la sala de empaques de la colonia, y se distribuyen en los nodos; el nodero guarda 
una ganancia (sugerida en un 20\%) para que la producción mantenga un precio accesible al bolsillo de los sectores populares.

- Venta directa y puerta a puerta: asimismo, la colonia recibe pedidos de bolsones, los cuales son entregados sin intermediación. A partir del decreto de Aislamiento Social Preventivo y Obligatorio (ASPO) en marzo 2020, los/ las productores/as de la Colonia 20 de Abril debieron acomodarse al nuevo escenario. Se realizaron dos estrategias complementarias: por un lado, se instauró el sistema de entrega a domicilio que generó un aumento exponencial de las ventas (se quintuplicaron), además de difundir la propuesta agroecológica de la colonia. Por otro, se construyeron nodos en los diferentes puntos del partido de Luján y General Rodríguez que funcionaban por encargo previo, y donde sus integrantes no pertenecen, necesariamente, a la UTT

- Canales por fuera de la UTT: si bien la organización promueve una propuesta colectiva, esta no ata a los productores a seguirla puesto que tienen la libertad de comercializar por fuera de los canales oficiales y de participar en otras ferias.

Durante 2020, en el contexto de pandemia por COVID-19, la colonia se consolidó como espacio de comercialización alternativa. La coyuntura promovió el debate sobre las inconsistencias entre producción y distribución, por lo que determinados sectores fueron alertados de los peligros que implican consumir alimentos "industrializados y ultraprocesados" (Aguirre, 2017). Esto, produjo que más familias empezaran a consumir productos agroecológicos (Urcola y Nogueira, 2020). Durante los meses que duró el ASPO, la colonia amplió el área de entrega de bolsones a más barrios, incluyendo el centro de Luján. Asimismo, se reorganizó la red de nodos de distribución y se añadieron localidades más alejadas y partidos vecinos hasta llegar, en la actualidad, a 37 puntos de comercialización. A pesar de esta situación atípica, se evidencia un interés creciente por la agroecología y los cambios en los hábitos de consumo. Además, la emergencia sanitaria instauró el debate sobre la necesidad de alimentos sanos para el sistema inmunológico, la dificultad de acceso a ellos y la relación entre alimentación y enfermedades (Naturaleza de Derechos, 2021) que fueron claves para sostener la propuesta de los nodos (Altieri y Nicholls, 2020; Liaudat, 2020).

En el actual contexto, el almacén de campo atrae a un colectivo creciente de consumidores de diverso nivel socioeconómico que se acercan a comprar alimentos saludables y que han declarado interés en recorrer el predio, charlar con los horticultores y conocer sus prácticas productivas (Castro et al., 2021). A su vez, la estrategia comunicacional de la UTT ha visibilizado estas ruralidades a escala provincial y nacional, siendo el caso de la colonia tomado como ejemplo de producción de políiticas desde abajo, y replicado en otros distritos con problemáticas similares.

\section{Educación}

Desde la UTT se han consolidado espacios de alfabetización en distintos territorios. El objetivo principal es generar y construir colectivamente herramientas de lectoescritura que les permitan a los pequeños productores finalizar los estudios obligatorios y acceder a carreras del nivel superior.

Hace aproximadamente 6 años, se comenzó con la idea de una escuela dentro de la colonia, debido a que los 
propios productores manifestaban sus deseos de estudiar, finalizar la escuela y adquirir nuevos conocimientos. De esta forma, ese deseo colectivo fue el puntapié inicial para comenzar a dar cuerpo a la escuela campesina, a través de una propuesta de educación popular. Primero, se organizó un curso de alfabetización. Luego, se buscó formalizar el trabajo realizado, lo que motivó que se iniciaran las gestiones con el Estado local para que funcionara en la colonia una escuela campesina de nivel primario. A mediados de 2016, a través de un acuerdo con el Estado Provincial, se logró la oficialización del Centro Educativo de Adultos № 703 (CEA) en el nivel de Ciclo de Alfabetización de Educación de Adultos; y en 2019, la Escuela Secundaria Campesina Agroecológica (Cens 451).

\section{Hacia un propuesta turística}

\section{Diagnóstico}

Desde el proyecto de extensión, se realizaron encuestas en el predio de la colonia, entre el 21 de diciembre de 2019 y el 18 de enero de 2020, mientras se llevaban a cabo ferias agroecológicas en el predio. Sin embargo, los resultados nos sirvieron para generar un diagnóstico en el trabajo de planificación participativa que se desarrolló con posterioridad, ya que se pudo realizar una aproximación a los intereses y demandas de los visitantes de la Colonia.

Los resultados de las mismas arrojaron que las principales motivaciones de los visitantes por comprar productos en la colonia fueron que estos eran agroecológicos (56,7\%). De este grupo, se destacaron la calidad y los precios accesibles con un $37,8 \%$ del total. El 18,9\%, respondió que apoyaban la pequeña producción a partir de la compra directa, con un claro componente ideológico. Este grupo resaltó que uno de los beneficios de realizar su compra en la colonia es apoyar a los/las pequeños/as productores/as de la Agricultura Familiar. En este sentido, la producción de alimentos sanos se diferencia de la agricultura de commodities por el contacto estrecho/directo entre productores y consumidores que no solo eligen el producto en sí mismo sino la carga social, cultural y políticas que conlleva. El 8, 1\% destacó los aspectos paisajísticos de la Colonia como el principal atractivo. Es decir, el circuito corto de comercialización no solo responde al abaratamiento de los costos por la reducción de la distancia física, sino también a la reconstrucción del vínculo productor-consumidor y a estrechar lazos de confianza y valores compartidos en torno a los alimentos (Craviotti y Soleno Wilches, 2015).

A su vez, entre las desventajas se identifica que el predio de la colonia se encuentra alejado del centro urbano o cabecera del partido, siendo necesario acercarse en vehículo propio o bien, depender de un transporte público poco eficiente. Sin embargo, varios encuestados explicaron que comparten vehículo con amigos, vecinos o familiares para abaratar el costo de traslado. Otro elemento observable es que quienes asisten a la feria o al almacén llevan sus propias bolsas, fundamentalmente de tela; salvo en los casos que realizan el pedido de bolsones.

Al consultar sobre qué actividades les interesaría a los visitantes encontrar en la colonia, expresaron la posibilidad de contar con talleres o capacitaciones sobre alimentación consciente y salud (40\%). El 26,7\% se refirió a aspectos productivos, como por ejemplo charlas y talleres sobre huertas familiares. El 33,3\% no determinó el tipo de capacitación requerida. La segunda actividad más solicitada se refiere a la música, tanto grabada como en vivo. Un 13,5\% sugiere que haya más días de feria. Finalmente, un $8 \%$ sugirió organizar visitas o recorridos guiados por la Colonia y la zona productiva en sí para "conocer 
lo que hay detrás de la compra" y que "den más a conocer la propuesta de agroecología" (Encuestas, 2020).

Por otra parte, un dato que surge de las encuestas, es la necesidad agregar una feria en el centro de Luján que incorpore otro tipo de producciones, tal como artesanías. Así, la feria en la Colonia 20 de Abril constituye un espacio público de intercambio y re-construcción de identidades (Craviotti y Soleno Wilches, 2015).

\section{Organización y planificación de la propuesta}

El proyecto de extensión en la colonia tiene como propósito generar una experiencia de desarrollo rural de la agricultura familiar y su eje principal es la valorización de la identidad campesina de los productores y productoras de la colonia. Esta identidad se construye por un lado, a través de los múltiples territorios (Haesbaert, 2011) que han transitado los/las productores/as antes de radicarse en el partido de Luján. Por otro, mediante las relaciones sociales y organizativas que los productores despliegan en el nuevo espacio. Algunas de ellas, se han convertido en el eje y parte del posicionamiento político de la colonia: la producción de alimentos sanos a precios populares, ambiental y socialmente sostenible, aportando a la soberanía alimentaria. Entendemos que estas propuestas son novedosas en el partido y que influyen en el debate por el acceso a la tierra y demás problemáticas de la AF a nivel nacional. Por lo que el proyecto de turismo, pensado junto con los productores, se enfocó en varios aspectos: la recuperación del patrimonio natural y cultural, la continuidad y permanencia de saberes y creencias culturales, el afianzamiento y reproducción de la vida campesina, y la transición agroecológica.

El ASPO promovió la reflexión sobre la potencialidad que generan los espacios rurales próximos a las ciudades como alternativa a la actividad turística. En este sentido, el caso de la colonia resulta una propuesta altamente atractiva por sus características identitarias vinculadas a la economía social y la agroecología. Asimismo, permite resguardar los bienes comunes y generar ingresos económicos alternativos, a partir de una experiencia directa para el visitanteconsumidor. El partido de Luján es una de las localidades bonaerenses con mayor tradición de turismo de fin de semana, además de formar parte de un corredor de pueblos rurales y gastronómicos. Esta propuesta de turismo rural ampliará la oferta hacia otro tipo de ruralidad, tal como lo han descrito los propios productores, "es un espacio de encuentro y de intercambio de conocimiento para que los visitantes conozcan y compren alimentos saludables" (visita predial, 2021).

Sobre las etapas de planificación, en una primera instancia, se realizó un encuentro participativo con productores a fin de determinar el tipo de turismo, el mensaje a transmitir y qué atractivos serán puestos en valor. En este proceso, se identificó que la colonia es un predio de producción y reproducción de la unidad familiar por lo que la propuesta de turismo tiene un doble objetivo: por un lado, presentar a los y las visitantes la experiencia real de la colonia; y por otro, no vulnerar la privacidad de las familias que viven allí.

Otro de los acuerdos, consistió en convocar a la Dirección de Turismo de la Municipalidad de Luján para capacitar a horticultores/as en las tareas de guía y manejo de grupos, como así también dar el reconocimiento a la propuesta de la colonia. 
Imagen 1: encuentro con productores en la Colonia 2021.

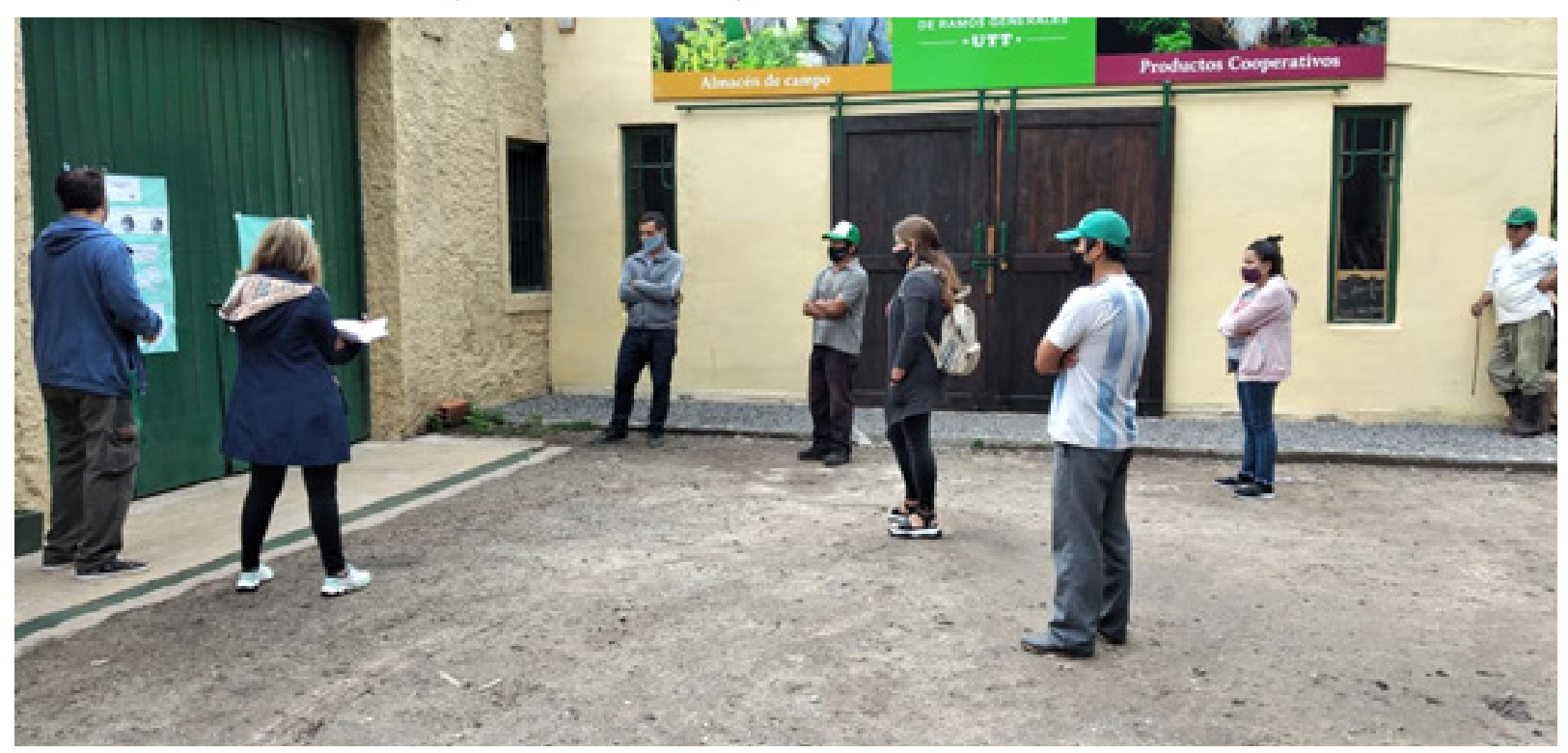

Fuente: elaboración propia.

Los talleres dieron como resultado la construcción de ejes y conceptos para la implementación del proyecto turístico. En ese sentido, la producción agroecológica es central para la propuesta turística puesto que permite analizar la necesidad y sostenimiento de los ecosistemas naturales. Estos, son imprescindibles para mantener la biodiversidad de la producción ya que los cordones boscosos aíslan las producciones sustentables de las convencionales, al tiempo que proveen insumos para su fertilización. Por ello, el suelo del bosque es muy valorado por los productores pues "tiene follaje que se pudre y es un abono que nosotros incorporamos a las plantas, hacemos un bocashi" (Visita Predial, 2021). Además, bajo este concepto los visitantes podrían visualizar todas las etapas del proceso productivo: desde la siembra hasta su comercialización en el almacén, sin dejar de lado lo organizativo y político, como otra de las partes fundamentales de una propuesta agroecológica (Sevilla Guzmán \& Woodgate, 2013).

Imagen 2: encuentro con productores en la Colonia 2021.

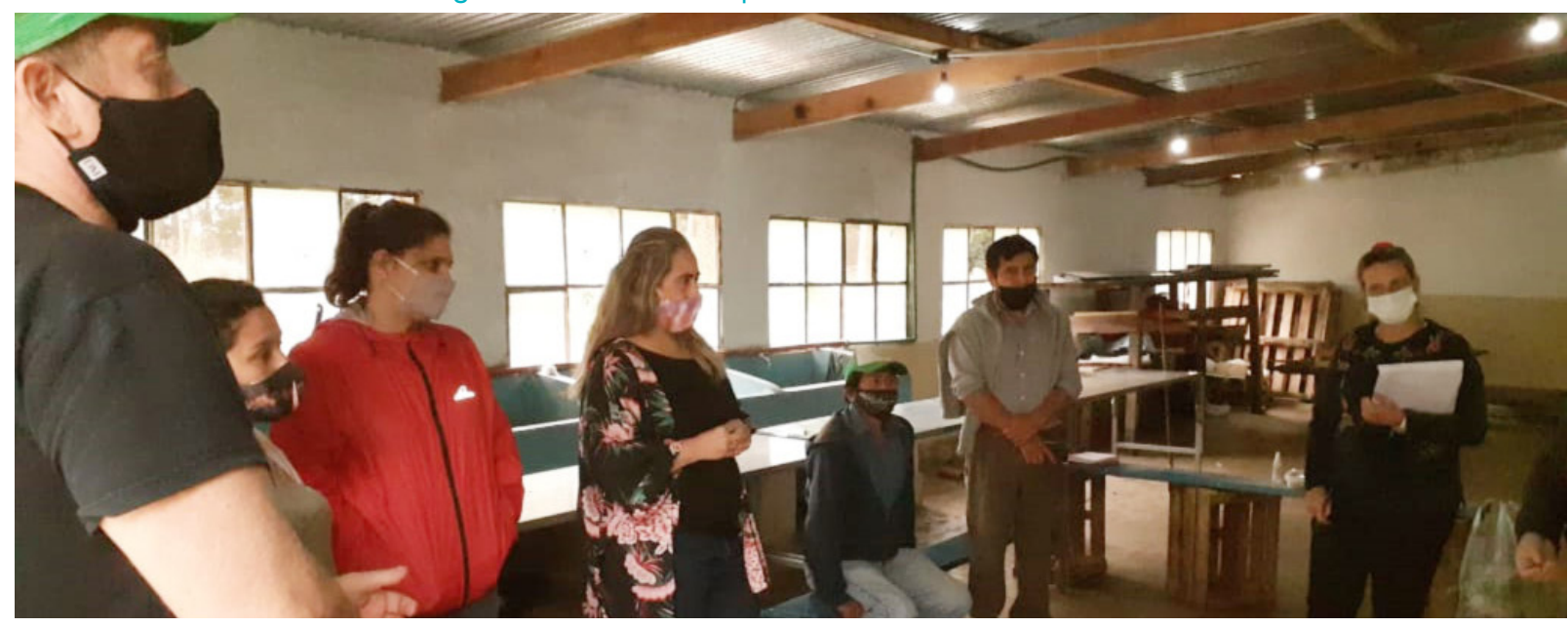

Fuente: elaboración propia. 
A su vez, estos talleres dieron forma a una propuesta de sendero que se realizará en grupos reducidos acompañados de un/a guía. Esto, retomaría aspectos de interés para los y las visitantes, teniendo en cuenta que se trata de un espacio donde las unidades domésticas están integradas a las productivas, lo cual requiere determinados cuidados. Se estima que el recorrido consta de aproximadamente 1,37 Km y con una duración de 50 minutos. Asimismo, atraviesa distintos espacios y paisajes propios del predio del ex Ramayón, como el bosque mixto, quintas, apiarios, plantinera, biofábrica, galpón de empaque, escuela, capilla y el Almacén de Campo que se detallan en la tabla 1.

\section{Tabla 1: postas del sendero}


ALMACÉN
El sendero inicia en el bosque mixto (imagen 3), rico en especies arbóreas, tanto nativas como exóticas. Algunas de las cuales tienen diversos usos como: fabricación de herramientas o medicina ancestral. También el suelo del mismo es fuente de insumos para la biofábrica, debido a la riqueza en microorganismos y materia orgánica. Es parte del predio y atractivo del mismo, se conserva con el objeto de ser amortiguamiento de las pulverizaciones realizadas por los campos vecinos y reserva de biodiversidad.

En las quintas o parcelas (imagen 4 y 5) se combinan cultivos agroecológicos alternando algunos a campo y otros en invernadero. El riego es por goteo para priorizar el ahorro de energía. Se utiliza el fertilizante producido en la biofábrica y abono.

En la Colonia paulatinamente se está incorporando el uso de invernáculos, teniendo en cuenta que la superficie cubierta no puede superar el $40 \%$ de la explotación.

Se cuentan también con espacios productivos de uso comunitario, como un monte de frutales. Este emprendimiento fue parte de un proyecto de extensión. Se espera que se pueda generar una producción para el autoconsumo.

Este es el espacio de fabricación, envasado y etiquetado de biopreparados. Cada semana se venden a productores del predio para poder comprar algunos insumos no producidos en la Colonia, necesarios para su elaboración.

Uno de los significados de este espacio, es hacer de vínculo con gran parte del recorrido, puesto que la tierra y las hojas del suelo del bosque son insumos para la preparación de fertilizante natural conocido como bocashi, de manera que ofrece ver una integración entre los sistemas naturales y los aspectos productivos.

En el marco del proyecto de turismo se espera que los biopreparados puedan ser vendidos a los visitantes. También se plantea como un espacio de charlas y talleres con los visitantes.

Se trata de edificios que datan de la construcción original del Instituto, por lo que presentan características históricas. Surge en 1930 como "Colonia de niños débiles" hasta que en 1932 pasó a ser un instituto de enseñanza primaria. En 1939 la Sociedad [de Beneficencia por doña Flora Ramayón de Martínez Campos] resolvió destinarlo para educación y aprendizaje de oficios manuales y rurales de varones débiles mentales pupilos que, con edades entre 10 y 20 años, provenían de otras instituciones de menores" (Crespi, 1999: 41).

En la capilla (imagen 7), los colonos reciben a un sacerdote para la celebración de la misa. Es un edificio que por su valor patrimonial histórico, se plantea como un atractivo a ser revalorizado y resignificado en el marco del proyecto de turismo.

En cuanto a la escuela (imagen 6), forma parte del edificio principal y se conecta con la capilla por un patio exterior donde se pueden observar murales que aluden a las luchas campesinas.

Se encuentra al finalizar el sendero (imagen 8 y 9) y es el canal de comercialización de los alimentos producidos en la Colonia y por cooperativas asociadas. Es el lugar donde visitantes y potenciales consumidores, pueden acceder a ellos y conocer su origen, también se proyecta como un espacio de descanso y esparcimiento. 
Imagen 3: recorrido por el sendero Bosque mixto.

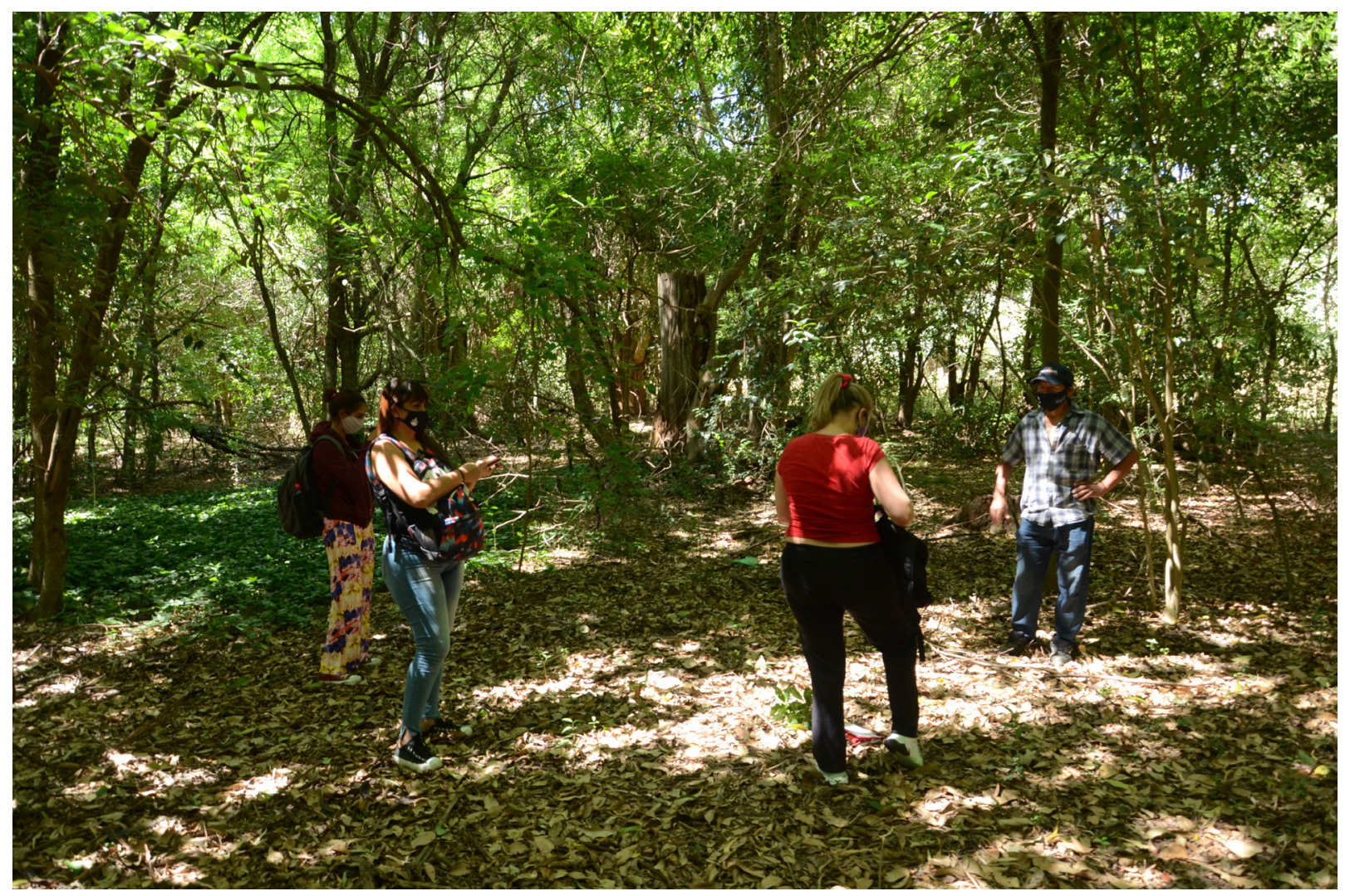

Fuente: elaboración propia.

Imagen 4: invernáculo




Imagen 5: producción a campo.

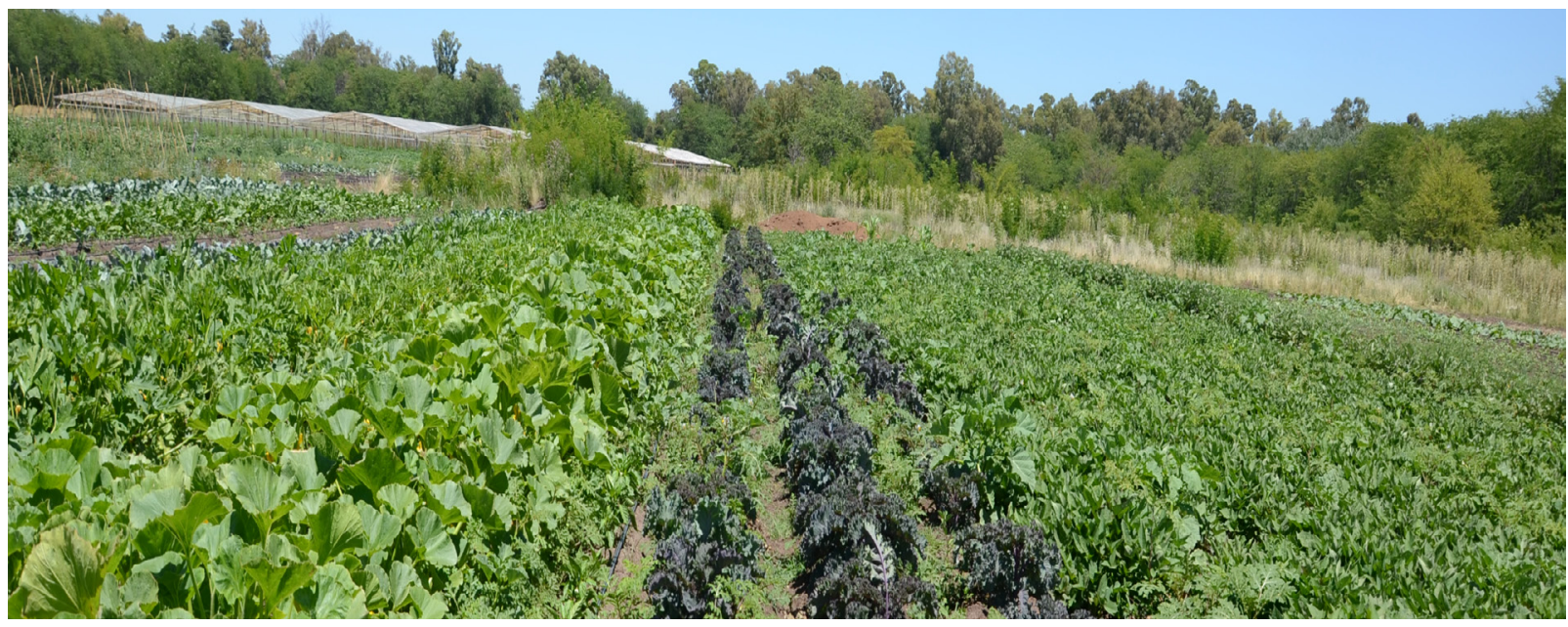

Fuente: elaboración propia.

Imagen 6: frente de la escuela.

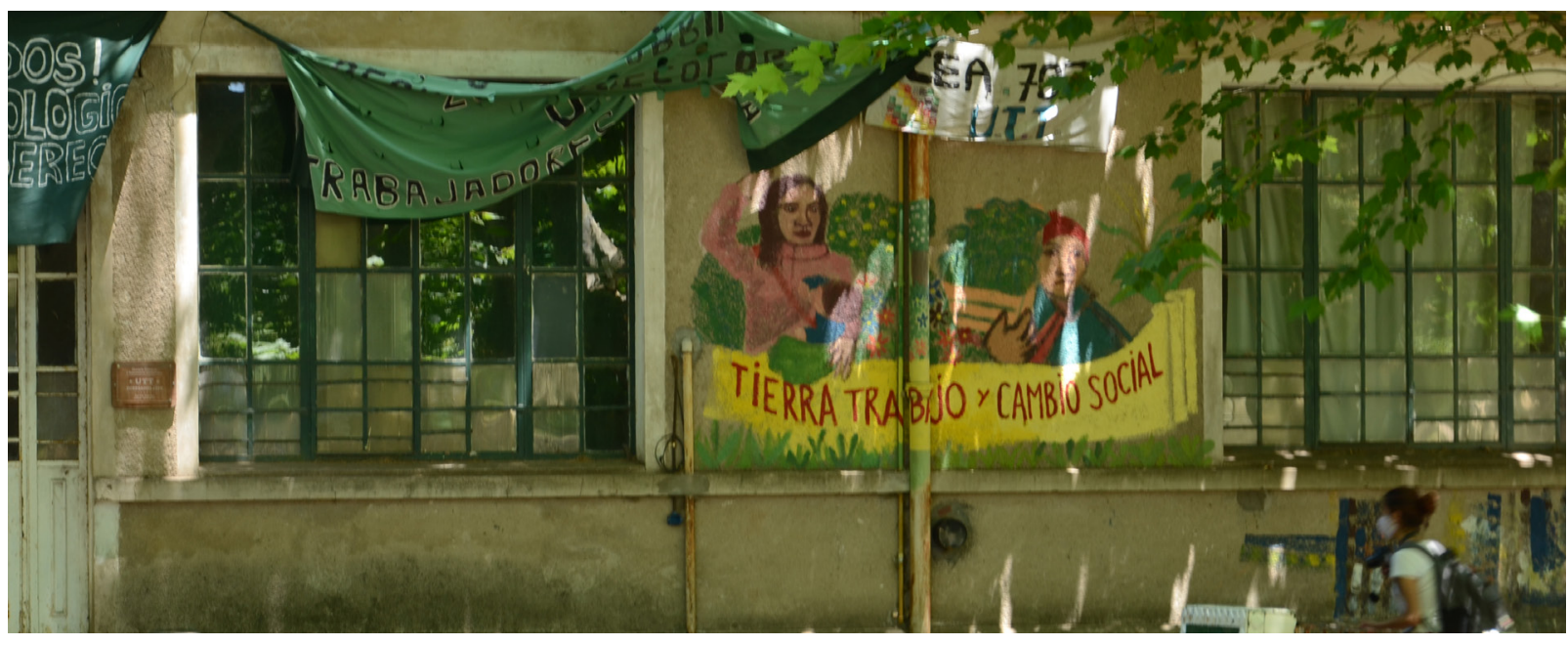

Fuente: elaboración propia.

Imagen 7: frente de la capilla.



Fuente: elaboración propia. 
Imagen 8: almacén de campo UTT.

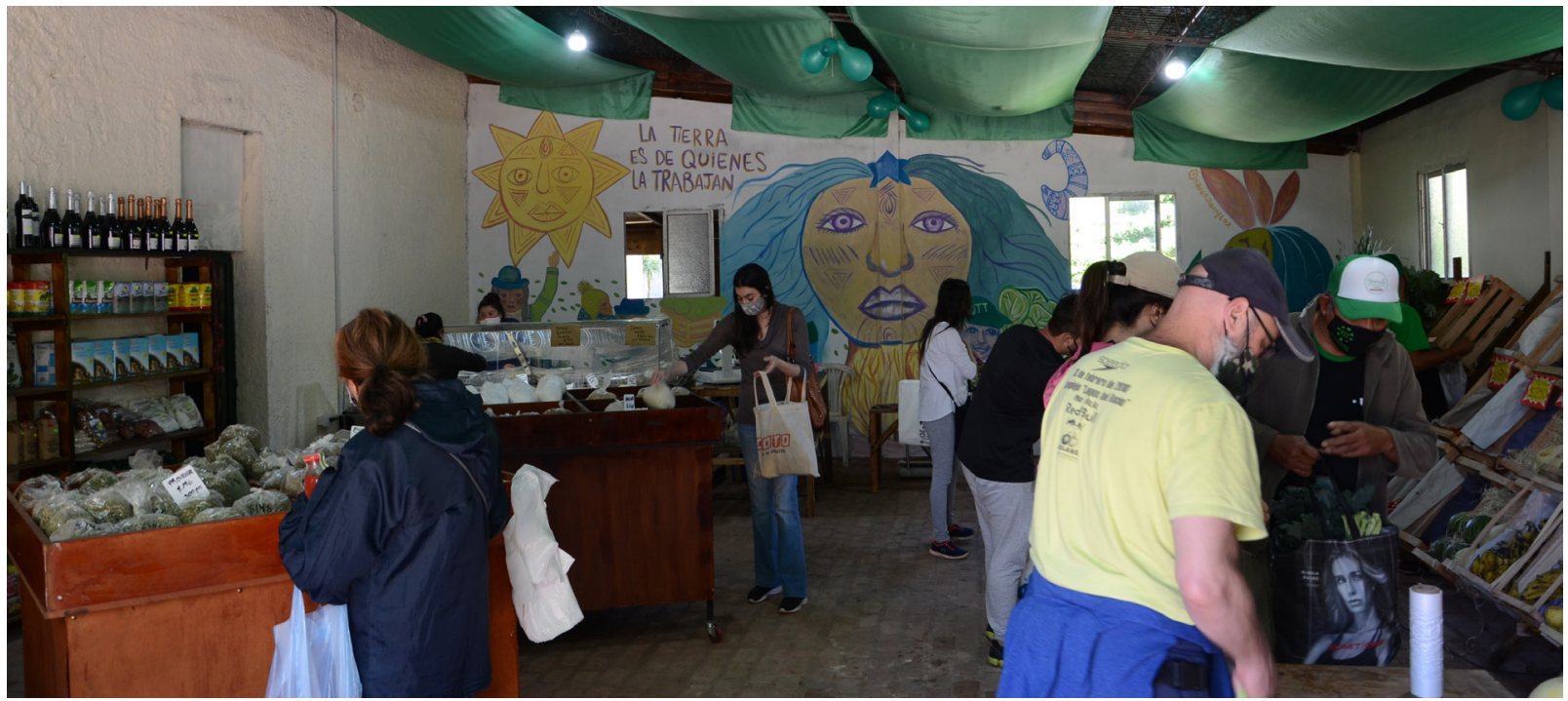

Fuente: elaboración propia.

Imagen 9: inauguración del almacén de Ramos Generales UTT - 24 de noviembre 2020.

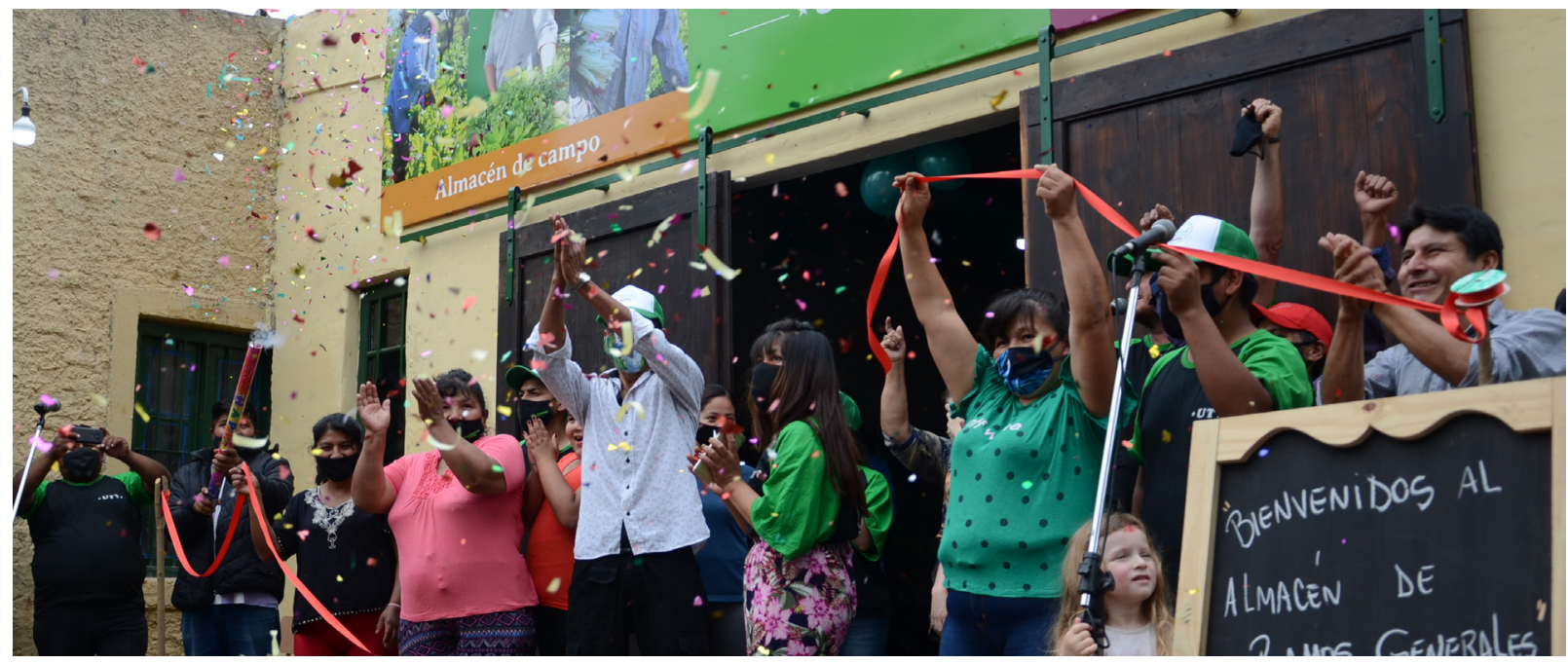

Fuente: elaboración propia.

Hacia una puesta en marcha

En la actualidad, los encuentros participativos tienen como eje la organización tanto material como logística de la propuesta turística. Esto se realiza mediante la coordinación con el municipio de Luján, la UTT, la colonia y otros grupos de extensionistas, con el propósito de sumar al proyecto diversas perspectivas, resultados de trabajo de campo y experiencias.

\section{Discusión o reflexiones finales}

Entendemos que la experiencia de la Colonia Agrícola 20 de Abril en Jáuregui, plantea la práctica agroecológica como una alternativa a la producción hortícola hegemónica del GBA. Asimismo, posibilita, desde una perspectiva 
política y de movimiento (Wezel, 2008), repensar las formas de apropiación territorial, a partir de organizaciones de la AF. En este sentido, la colonia no solo comprende experiencia desde abajo, también revaloriza la forma de producción y la Economía Social Solidaria que se convierten en atractivos para el turismo.

El proyecto de extensión acompaña esa necesidad que visibilizada por los productores y que trata de apuntalar un proceso que se daba de forma espontánea. Los consumidores muchas veces consultaban por la posibilidad de recorrer el predio, visitar las quintas y aprender la historia de la Colonia.

Por eso, entendemos que a través de esta experiencia, y de forma colectiva, se pueden integrar proyectos de extensión de diversas organizaciones con la intervención de diferentes actores sociales: productores, productoras, universidades, extensionistas, Municipalidad de Luján, SENASA, Secretaría de AF Campesina e Indígena e INTA.

Si bien este proyecto se encuentra en construcción y a pesar de la incertidumbre que plantea la actual pandemia, el grado de avance en materia de acuerdos, tareas y objetivos nos permite pensar que la colonia será un destino turístico relevante en el partido de Luján; sobre todo ante la valorización del turismo de fin de semana, próximo a las ciudades y en espacios abiertos. También resulta una alternativa para los y las jóvenes de la colonia que no desean continuar con la producción hortícola propia, por lo que permitiría profundizar y acceder a nuevas actividades en el medio rural, así como continuar con estudios terciarios.

En el proceso de construcción de esta propuesta valoramos las estrategias participativas donde se intenta propiciar la construcción de espacios horizontales y con una mirada integradora sobre el turismo. En esa línea, identificamos varios atractivos. Por un lado, la producción agroecológica de alimentos, por otro, los aspectos que hacen a la identidad de los horticultores, su origen migratorio, trayectoria y creencias. También, el proceso de acción colectiva dentro de la organización que les permitió acceder a la tierra. A su vez, el predio posee historia y rugosidades que permiten pensarlo como atractivo patrimonial y resignificarlo en el marco de esta propuesta. Ejemplos de esto son la capilla y ciertos edificios que en la actualidad están habitados por las familias, pero que antes cumplían funciones institucionales.

La Colonia Agrícola 20 de Abril Darío Santillán construye una mirada integral sobre la producción de alimentos y entiende la agroecología como una forma de vida. Por ello, pensamos que no solo se trata de un atractivo turístico, se trata de la construcción de una nueva ruralidad alternativa de resistencia y solidaridad (Castro, 2018). A su vez, constituye un faro que invita a crear y recrear nuevas experiencias de ruralidades alternativas en la región. 


\section{Referencias bibliográficas}

Aguirre, P. (2017). Una historia social de la comida. Buenos Aires: Lugar.

Altieri, M. \& Nicholls, C. (6 de abril de 2020) La agroecología en tiempos del COVID-19. CLACSO. https://www. clacso.org/la-agroecologia-en-tiempos-del-covid-19/-

Bell, D. (2006). Variations on the rural idyll. Handbook of Rural Studies, 149-160. http://dx.doi. org/10.4135/9781848608016

Bertoncello, R. (Mayo de 2002). Turismo y territorio. Otras prácticas, otras miradas. V Jomadas Nacionales de Investigación-Acción en Turismo. Centro de Investigaciones Turísticas de la Universidad Nacional de Mar del Plata, Mar del Plata, Argentina.

Caracciolo, Mercedes (2014) "Construcción de tramas de valor y mercados solidarios" En García, A (compilador) Espacio y Poder en las políticas de Desarrollo del siglo XXI. (Buenos Aires: Agencia Nacional de Investigaciones científicas y técnicas. CEUR/CONICET)

Castro, G., et al. (2021) Turismo rural en la colonia agrícola "20 de Abril Darío Santillán", Luján (Buenos Aires). III Jornadas Internacionales y V Nacionales de Ambiente. Soberanía y Gestión de los Bienes Naturales Comunes. [Trabajo aceptado - en prensa] Hurlingham, Argentina.

Castro, G. D. (11 al 14 de septiembre, 2019). La horticultura en la interfase rural-urbana. Aproximación a las trayectorias de los horticultores del partido de Luján (PBA). III Congreso Internacional de Geografía Urbana (CIGUUNLu) Luján, Argentina.

Castro, G. (2018). La producción hortícola en el periurbano noroeste. En María Fernanda, G. M., \& Federico, V. (coords.) La Agricultura Familiar, entre lo rural y lo urban, pp. 132-160. Luján: EDUNLu

Castro, H. (2018). Lo rural en cuestión: perspectivas y debates sobre un concepto clave. En H. Castro (ed.) Lo rural en redefinición. Aproximaciones y estrategias desde la Geografía, pp. 19-48. Buenos Aires: Biblos.

Castro, G. \& Kindernecht, N. (6-8 de septiembre de 2017). Conflictos ambientales en el partido de Luján. Aproximación a las tensiones en torno a las aplicaciones de agroquímicos. Actas del II Congreso Internacional de Geografía UrbanaCiudades bajo presión. Periferias como opción. Universidad Nacional de Luján, Luján, Argentina.

Craviotti, C., \& Soleno Wilches, R. (2015). Circuitos cortos de comercialización agroalimentaria: un acercamiento desde la agricultura familiar diversificada en Argentina 16(33). 
Craviotti, C. (2007). Tensiones entre una ruralidad productiva y otra residencial: El caso del partido de Exaltación de la Cruz, Buenos Aires, Argentina. Economía, Sociedad y Territorio, VI(23), 745-772.

Crespi, L. (1999). Instituciones de la Sociedad de beneficencia y asistencia social (1823 - 1952 Tomo I. Archivo General de la Nación.

García, M., \& Le Gall, J. (Marzo de 2009). Reestructuraciones en la Horticultura del AMBA: tiempos de boliviano. IV Congreso Argentino y Latinoamericano de Antropología Rural. Mar del Plata, Argentina.

García, M. (2011). Proceso de acumulación de capital en campesinos. El caso de los horticultores bolivianos de Buenos Aires (Argentina). Cuadernos de desarrollo rural, 8(66), 47-70.

García, M. (2015). Modelo productivo irracionalmente exitoso. Agricultura Familiar, 114, 190-201.

García, M. (2015b). Colonia hortícola o Barbarie. Boletín Hortícola, 19(53), 19-26.

Giarracca, N. (2002). Movimientos sociales y protestas en los mundos rurales latinoamericanos: Nuevos escenarios y nuevos enfoques. Sociologias, s/v(8), 246-274. https://doi.org/10.1590/s1517-45222002000200011

González Maraschio, M. F., Kindernecht, N, \& Castro, G. (2019) Movilidades y trayectorias de la agricultura familiar en la frontera rural-urbana de la aglomeración Gran Buenos Aires, Argentina. XXI Jornadas de Geografía de la Universidad Nacional de La Plata. La Plata, Argentina.

González Maraschio, F., Kindernecht, N. \& Castro, G. (2018). Movilidades y trayectorias de la Agricultura Familiar en la frontera rural-urbana de la Aglomeración Gran Buenos Aires, Argentina. (Jornadas P). Facultad de Humanidades y Ciencias de la Educación, UNLP. La Plata, Argentina.

González Maraschio, et al. (2017). Productores agropecuarios de Luján (PBA). Estrategias productivas en un área de interfase rural-urbana. X Jornadas Interdisciplinarias de Estudios Agrarios y Agroindustriales Argentinos y Latinoamericanos. Buenos Aires, Argentina.

González Maraschio, et al. (2016) Conflictos ambientales en el partido de Luján (PBA). La complejidad ambiental en un espacio rururbano. En Gabriela P., Lorena H. (coords.) Geografías por venir. Neuquén: Universidad Nacional del Comahue.

González Maraschio et al. (2015). Dinámicas y conflictos entre el campo y la ciudad. Anuario de la División Geografía.

González Maraschio, F. (2011). Nuevas dinámicas rurales. Transformaciones socio-productivas recientes y usos del 
territorio en el partido de San Andrés de Giles (PBA). FLACSO. Buenos Aires, Argentina. https://www.flacso.org.ar/ formacion-academica/estudios-sociales-agrarios-2/tesis/

González Maraschio, F. (2012). Identidades y conflictos en territorios de frontera rural-urbana. Eutopía - Revista de Desarrollo Económico Territorial, 95-115. https://doi.org/10.17141/eutopia.3.2011.1021

Haesbaert, R. (2011). El mito de la desterritorialización: del "fin de los territorios" a la multiterritorialidad. Buenos Aires: Siglo Veintiuno.

Kay, C. (2008). Reflections on Latin American Rural Studies in the Neoliberal Globalization Period: A New Rurality? Development and Change, 39(6), 915-943. https://doi.org/10.1111/i.1467-7660.2008.00518.x

Kindernecht, N. (2019) Dos experiencias de producción agroecológica en el partido de Luján. En: González Maraschio, M. F. y Villarreal F. (Coord.) "La Agricultura Familiar, entre lo rural y lo urbano" p.242-260. Luján: EDUNLu.. Libro recientemente publicado. http://www.edunlu.unlu.edu.ar/?q=node/233

Liaudat, S. (2020) La pandemia está directamente relacionada al sistema alimentario agroindustrial. Revista Ciencia, Tecnología y Política, 3(5) https://doi.org/10.24215/26183188e041

Naturaleza de Derechos (20 de febrero, 2021). En abril de 2020, al mes de iniciada la pandemia por COVID-19, desde naturaleza de derechos (...) [publicación en el muro] Facebook. https://m.facebook.com/story.php?story_fbid=3 $723911841024509 \&$ id $=819769671438755$

Pérez Winter, C. (2017). Del turismo "cultural" al "rural": un caso de la Pampa bonaerense (Argentina). Cuadernos de Geografía: Revista Colombiana de Geografía, 26(2), 261-278. https://doi.org/10.15446/rcdg.v26n2.59105

Sarandón, S. J., \& Flores, C. C. (2014). Agroecología: bases teóricas para el diseño y manejo de Agroecosistemas sustentables. La Plata: EdULP. www.editorial.unlp.edu.ar

Sarandón, S. J., \& Flores, C. C. (2014). Agroecología: bases teóricas para el diseño y manejo de agroecosistemas sustentables. La Plata: EdULP www.editorial.unlp.edu.ar

Schejtman, A., \& Berdegué, J. (2007). Desarrollo Territorial Rural. En J. Bengoa (Ed.), Territorios Rurales, pp. 45-82. Centro Latinoamericano para el Desarrollo Rural. Chile: Catalonia

Sevilla Guzmán, E., \& Woodgate, G. (2013). Agroecología: fundamentos del pensamiento social agrario y teoría sociológica. Agroecología 8, 27-34. 
Sili, M. E. (2019). La reconstrucción de la ruralidad en Argentina. Agenda para una política de desarrollo rural. En Christope, A.o \& Roberto, B. C..(Eds.), Desarrollo local y nuevas ruralidades en Argentina. San Martín: EdiUNS.

Urcola, M., \& Nogueira, M. E. (2020). Producir alimentos en tiempos de pandemia. El rol esencial de la agricultura familiar. Temas y Debates, O(0), 267-275. https://doi.org/10.35305/tyd.v0i0.503

Wezel, A., Bellon et al. (2009). Agroecology as a science, a movement and a practice. A review A review. Agronomy for Sustainable Development, Springer Verlag/EDP Sci-ences/ Agroecology as a science, a movement and a practice. A review. Sustain. Dev, 29(4), 503-515. https://doi.org/10.1051/agro/2009004ï

Zusman, P. \& Pérez Winter, C. (2018) Las áreas rurales y el patrimonio histórico - cultural. En Hortensia, C.. \& Mariana, A. (Coord). Lo Rural en redefinición. Aproximaciones y estrategias desde la Geografía. pp. 231- 252. Buenos Aires: Biblios. 